\title{
DNA Nuclear Targeting Sequences for Non-Viral Gene Delivery
}

\author{
Ethlinn V. B. van Gaal • Ronald S. Oosting • Roel van Eijk • Marta Bakowska • Dries Feyen • Robbert Jan Kok • Wim E. Hennink • \\ Daan J. A. Crommelin • Enrico Mastrobattista
}

Received: 16 December 2010 / Accepted: 21 February 2011 / Published online: 18 March 2011

(C) The Author(s) 2011. This article is published with open access at Springerlink.com

\begin{abstract}
Purpose To evaluate if introduction of DNA nuclear Targeting Sequences (DTS; i.e. recognition sequences for endogenous DNA-binding proteins) in plasmid DNA (pDNA) leads to increased transfection efficiency of non-viral gene delivery by virtue of enhanced nuclear import of the pDNA.

Methods A set of DTS was identified and cloned into EGFPreporter plasmids controlled by the CMV-promoter. These pDNA constructs were delivered into A43I and HeLa cells using standard electroporation, pEI-based polyfection or lipofection methods. The amount of pDNA delivered into the nucleus was determined by qPCR; transfection efficiency was determined by flow cytometry.

Results Neither of these DTS increased transgene expression. We varied several parameters (mitotic activity, applied dose and delivery strategy), but without effect. Although upregulated transgene expression was observed after stimulation with TNF$\alpha$, this effect could be ascribed to non-specific upregulation of transcription rather than enhanced nuclear import. Nuclear copy numbers of plasmids containing or lacking a DTS did not differ significantly after lipofectamine-based transfection in dividing and non-dividing cells.
\end{abstract}

E. V. B. van Gaal • R. van Eijk • M. Bakowska • D. Feyen • R. J. Kok ·

W. E. Hennink • D. J. A. Crommelin • E. Mastrobattista $(\square)$

Department of Pharmaceutics

Utrecht Institute of Pharmaceutical Sciences, Utrecht University

3584 CA, Utrecht, The Netherlands

e-mail: e.mastrobattista@uu.nl

\section{R. S. Oosting}

Department of Pharmacology

Utrecht Institute of Pharmaceutical Sciences, Utrecht University

3584 CA, Utrecht, The Netherlands

D. J. A. Crommelin

Dutch Top Institute Pharma

Leiden, The Netherlands
Conclusion No beneficial effects of DTS on gene expression or nuclear uptake were observed in this study.

KEY WORDS DNA. DNA nuclear Targeting Sequences . non-viral gene delivery. nuclear import

\section{INTRODUCTION}

Non-viral gene therapy is challenged by inefficient delivery at the level of intracellular processing. Several barriers have been described and studied, including failure to escape from vesicular structures (1,2), lysosomal degradation, enzymatic degradation in the cytosol (3), entrapment in the highly viscous and crowded cytosol $(4,5)$, lack of transport towards the nucleus (6-9) and uptake into the nucleus (10-15), and finally inefficiency of transcription and/or translation (16-19). Capecchi et al. (20) showed that microinjection of plasmid DNA directly into the nucleus resulted in transgene expression in $50 \%-100 \%$ of the cells, whereas cytoplasmic injection resulted in $<0.01 \%$ of transgene expressing cells. This observation clearly indicates that transport into the nucleus is the major bottleneck for successful non-viral gene delivery.

The nucleus is a double membrane organelle that is wellseparated from the rest of the cell. Exchange of molecules requires transport via one of the approximately 2,000 nuclear pore complexes (NPCs) per nucleus (21). NPCs allow passive diffusion of proteins up to $40 \mathrm{kDa}$ or particles of approximately $9 \mathrm{~nm}$ or DNA molecules of 210-350 bp $(4,22-24)$. These limits are well below sizes of DNA complexes $(\sim 100-500 \mathrm{~nm})$ and of plasmids $(\sim 6,000 \mathrm{bp})$ generally used for gene delivery studies. Large macromolecules, such as viral proteins and host proteins with a function in the nucleus (i.e. heterogeneous nuclear ribonucleoprotein Al (hnRNP), transcription factors, poly- 
merases), are able to gain access to the nucleus. These proteins were discovered to have consensus sequences, called nuclear localization signals (NLSs), which can interact with importin- $\alpha$, importin- $\beta$ or transportin. The formed complexes are then docked to the NPCs, and the protein is shuttled to the inner membrane of the nucleus. Many efforts have been made to mimic this process by incorporating NLSs in gene delivery complexes, mostly by using the consensus sequence NLSs of the Simian Virus 40 (SV40) large T antigen, but unfortunately success has been highly variable and generally disappointing (10,11,22,2533). An elegant alternative strategy was first presented by Dean et al. Based on the finding by Graessmann et al. (34) that an enhancer region within the SV40 viral DNA facilitated nuclear import, Dean et al. examined usability of this sequence for non-viral gene delivery and named it DNA nuclear Targeting Sequence (DTS) (12,35-37). In subsequent studies, it was found that the absence or presence of the SV40 origin of replication and early promoter region was critical for nuclear uptake of naked plasmids from cytosol in the absence of cell division (35), and a 72-bp region was identified to be sufficient to establish this effect (36). Inhibitor studies revealed that plasmid import occurred via the same pathway as signalmediated protein import and that transcriptional activity of the cell was required for the process to occur (35). Based on these findings, the following mechanism of DTS-mediated nuclear uptake was postulated: (1) transcription factors (TFs) present in the cytosol bind to their recognition sequences present in the plasmid via their DNA-binding domain, (2) NLSs naturally present in TFs interact with importin- $\alpha$ and subsequently with importin- $\beta$, leading to active transport towards the nucleus and docking of the TF/plasmid complex to the NPG (12).

After establishing this principle, several applications and variations have been studied. The DTS effect was shown to occur in several cell types upon microinjection, electroporation and transfection (35-37) and was confirmed in vivo (38-40). By replacing the heterogeneous SV40 sequence that is responsive to various TFs, including $\mathrm{NF} \kappa \mathrm{B}$ and $\mathrm{SP} 1$, by consensus sequences for nuclear factor kappa B (NFкB) (41-43) or glucocorticoid responsive elements (GREs) (44), plasmid import could be mediated via a specific pathway and stimulated via TNF- $\alpha$ or corticosteroids, respectively.

In this study we aimed to further optimize the DTS effect for non-viral gene delivery. A range of constructs with various DTSs based on the heterogeneous SV40 DTS, $\mathrm{NF \kappa B}$ and GRE consensus sequences was prepared and tested for their relative potential to enhance transfection efficiency. Furthermore, the relation between cytosolic accessibility of plasmid DNA, which is strongly carrierdependent, and the DTS effect was investigated by comparing results upon electroporation (no carrier), trans- fection with lipofectamine (dissociates prior to nuclear uptake (45)) and transfection with $22 \mathrm{kDA}$ linear pEI (shown to deliver DNA into the nucleus as intact complexes $(41,46))$. As we did not observe any significant differences between the constructs tested, we continued to explore the reason for this discrepancy with results published by others. To be able to distinguish effects at the level of transcription and of translocation, we quantified nuclear uptake of plasmids by quantitative PCR on isolated cell nuclei.

\section{MATERIALS AND METHODS}

\section{Materials}

All chemicals and reagents were purchased from Sigma (St. Louis, USA) unless stated otherwise. Other chemicals used were Hepes (99\%) and magnesium chloride, $\mathrm{MgCl} 2 \cdot 6 \mathrm{H} 2 \mathrm{O}$ (Acros Organics BVBA, Geel, Belgium); sodium chloride and ethanol (Merck, Darmstadt, Germany); potassium chloride (ICN Biomedicals, Aurora, USA); diethylether (Biosolve, Valkenswaard, The Netherlands); phosphatebuffered saline (PBS) (B. Braun Melsungen AG, Melsungen); fetal bovine serum (FBS; Integro, Zaandam, The Netherlands), Trypsin/EDTA 10×, Plain DMEM (Dulbecco's modification of Eagle's medium, with 3.7 g/l sodium bicarbonate, $1 \mathrm{~g} / \mathrm{l}$ l-glucose, L-glutamine) and antibiotics/antimycotics (penicillin, streptomycin sulphate, amphotericin B; PAA Laboratories GmbH, Pasching, Austria), TNF- $\alpha$ (rh TNF- $\alpha$; R\&D Systems, Minneapolis, USA).

TOPO TA Cloning Kit, TOP10 E. Coli bacteria, propidium iodide (PI), Lipofectamine ${ }^{\mathrm{TM}} 2000$ (lipofectamine), Opti-MEM® I Reduced Serum Medium (optimem), UltraPure $^{\text {TM }}$ Buffer-Saturated Phenol (TE-saturated phenol) and UltraPure $^{\text {TM }}$ Phenol:Chloroform:Isoamyl Alcohol (25:24:1, v/v) were purchased from Invitrogen (Oregon, USA).

All restriction enzymes and other DNA-modifying enzymes, RNase (RNase I, DNase- and protease-free), Proteinase K (recombinant, PCR grade) and DNA ladders were purchased from Fermentas (St. Leon-Rot, Germany). The oligonucleotides used for PCR reactions, sequencing and cloning were synthesized by Eurogentec S.A. (Seraing, Belgium). NucleoSpin Extract II DNA kits and Nucleobond PG Endotoxin Free kits for plasmid purification were obtained from Bioke (Macherey-Nagel, Bioke, Leiden, The Netherlands). LabelIT Cy5 Nucleic Acid Labeling Kit was purchased from Mirus Bio, Madison, WI, USA.

\section{Cloning of Plasmid Constructs}

Plasmid pCMV/EGFP was constructed from pShooter (Invitrogen, Oregon, USA); the EGFP coding sequence from 
pEGFP-N1 (bp 613-1410; Clontech, Saint-Germain-enLaye, France) was amplified by PCR and cloned into the multiple cloning site of pShooter from which the nuclear localization signal (NLS)-tag coding sequence was removed with NotI and XbaI restriction enzymes.

pCMV/EGFP was digested with DraIII and KasI to remove the complete SV40 ori and enhancer region. After purification from a $1 \%$ agarose gel, vector DNA was ligated to a piece of synthetic DNA obtained by annealing complementary oligonucleotides 1 (Table I), and ligation product was transformed into $E$. coli TOP10 cells by standard heat-shock procedure. Plasmids were isolated using Nucleobond PC Endotoxin Free kits, and identities were confirmed by restriction analysis and sequencing.

The resulting plasmid, pCMV/EGFP_noDTS_Spl, was further digested with BamHI and HindIII. The large fragment was purified from a 1\% agarose gel and either blunted and self-ligated to result in plasmid $\mathrm{pCMV/}$ EGFP_noDTS or ligated to pieces of synthetic DNA obtained by annealing complementary oligonucleotides 26 (Table I). Ligation products were transformed into E. Coli Top10 bacteria, and plasmids were isolated using Nucleobond PC Endotoxin Free kits. Plasmids were quantified by $260 \mathrm{~nm}$ absorbance measurement, and plasmid identity and quality were analyzed on 1\% agarose gels before and after digestion and 260/280 ratio measurements. Sequences of all plasmid constructs were verified by sequencing using oligo 7 (Table I) as primers (outsourced to Baseclear, Leiden, The Netherlands).

\section{DNA Labeling}

Plasmids were covalently labeled with Cy5 according to a modified version of the manufacturer's protocol: DNA was incubated overnight with a labeling mixture at room temperature and purified using ethanol precipitation. DNA was quantified and checked for purity by measuring the absorbance at 260 and $280 \mathrm{~nm}$ in a Nanodrop Spectrophotometer (Wilmington, DE USA). On average, 1 Cy5-molecule was bound per $150 \mathrm{bp}$, as calculated according to the manufacturer's instructions.

\section{Cell Culture}

Human epithelial ovarian carcinoma cells (HeLa) and human epidermoid carcinoma cells (A431) were grown in DMEM supplemented with antibiotics/antimycotics and $10 \%$ or $7.5 \%$ heat-inactivated FBS, respectively. Cells were maintained at $37^{\circ} \mathrm{C}$ in a $5 \% \mathrm{CO} 2$ humidified air atmosphere and split twice weekly. Both cell lines were kindly given by the Institute of Biomembranes (Utrecht University, The Netherlands). Cells were confirmed to be free from mycoplasm by periodical testing with a MycoAlert ${ }^{\circledR}$ Mycoplasma Detection Kit (Lonza, Verviers, Belgium).

Table I Sequences of Oligonucleotides Used for Preparation of New Constructs (BamHI and HindllI)

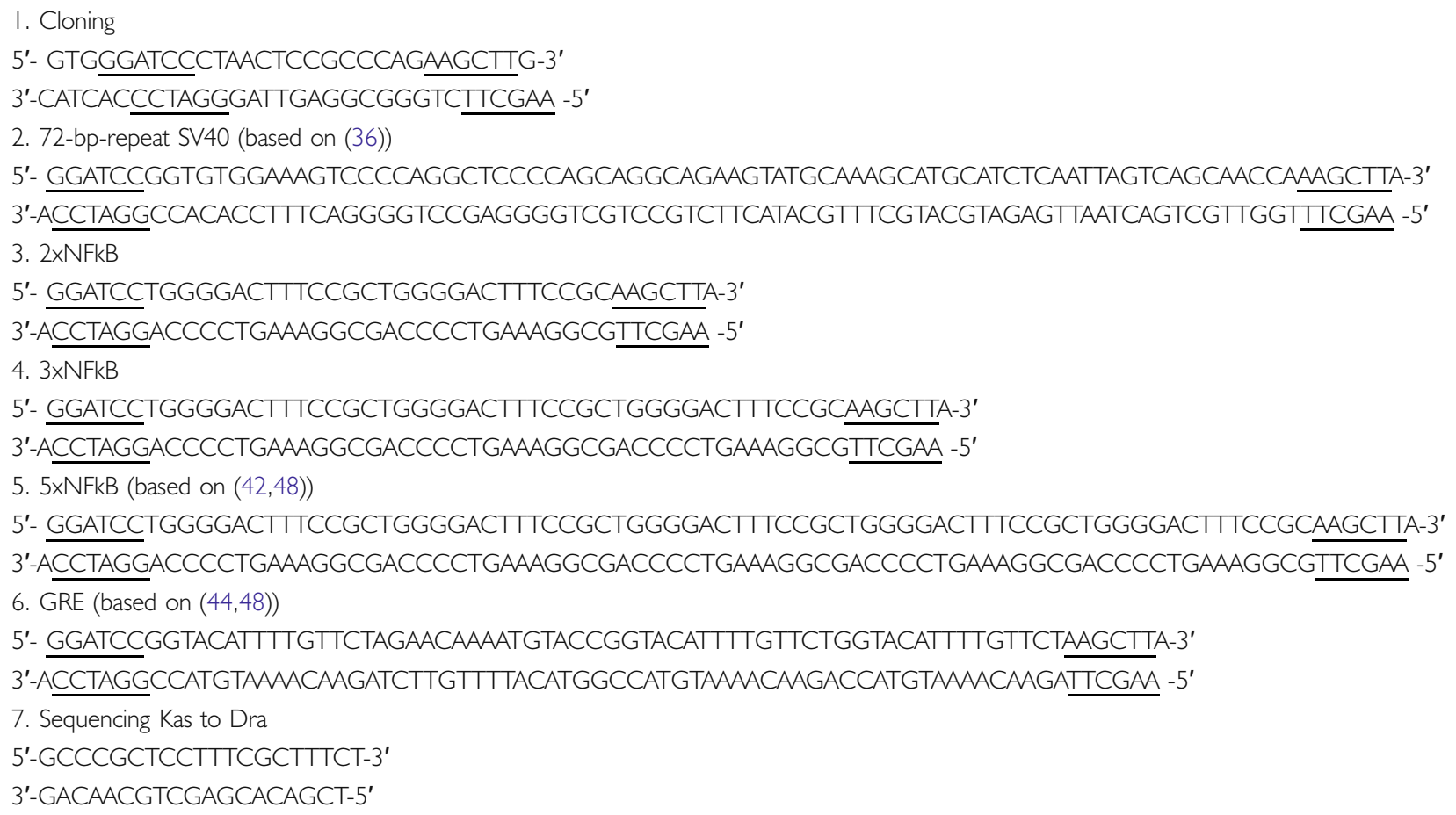




\section{Preparation of the Complexes}

pEI-polyplexes were prepared at an N/P ratio of six by adding four volumes of pEI (Exgen500; MBI Fermentas, St Leon-Rot, Germany) solution to one volume of a $50 \mu \mathrm{g} / \mathrm{ml}$ DNA solution, mixing by pipetting and incubating $30 \mathrm{~min}$ at room temperature. pEI-polyplexes were prepared in Hepes-buffered saline (20 mM Hepes, $150 \mathrm{mM} \mathrm{NaCl}$; pH 7.4 (HBS)). Lipofectamine-complexes were prepared at a ratio of $2 \mu \mathrm{l}$ lipofectamine per $1 \mu \mathrm{g}$ DNA by adding four volumes of lipofectamine solution to one volume of a $50 \mu \mathrm{g} / \mathrm{ml}$ DNA-solution (both diluted in optimem), mixing by pipetting and incubating $30 \mathrm{~min}$ at room temperature.

\section{Transfection}

For studies in dividing cells, 40,000 (HeLa) cells were seeded per well into 24-well tissue culture plates $24 \mathrm{~h}$ prior to transfection, such that $60 \%-70 \%$ confluency was reached on the day of transfection. For studies in non-dividing cells, 40,000 (HeLa) cells were seeded per well into 24-well tissue culture plates $48 \mathrm{~h}$ prior to transfection, and medium was replaced by complete medium supplemented with $15 \mu \mathrm{M}$ aphidicolin. Cells were continuously exposed to aphidicolin from at least 16 hours prior to transfection until time of analysis.

Immediately prior to transfection, the culture medium was refreshed with $500 \mu$ l DMEM medium, supplemented with 10\% FBS (and $15 \mu \mathrm{M}$ aphidicolin where applicable). One hundred $\mu \mathrm{l}$ of the polyplex or lipoplex samples (corresponding to $1 \mu \mathrm{g}$ DNA/well) were added per well, and after $4 \mathrm{~h}$ incubation, medium was replaced with fresh DMEM supplemented with $10 \%$ FBS (and $15 \mu \mathrm{M}$ aphidicolin where applicable). Cells were incubated for indicated times at $37^{\circ} \mathrm{C}$ in a $5 \%$ CO2 humidified air atmosphere until analysis. Experiments were performed in triplicate.

\section{Electroporation}

Cells were harvested by trypsin/EDTA (T/E) treatment, counted and diluted to $1.1 \cdot 10^{6} \mathrm{cells} / \mathrm{ml}$ in $20 \mathrm{mM}$ Hepes in
PBS (pH 7.4). DNA was diluted to $2 \mu \mathrm{g}$ DNA (or as indicated) into $25 \mu \mathrm{l}$ Hepes buffer. Twenty five $\mu$ l DNA solution was added to $225 \mu \mathrm{l}$ cell suspension and incubated on ice for $10 \mathrm{~min}$. After addition of $250 \mu \mathrm{l}$ Hepes buffer, the sample was transferred into an electroporation cuvette and electroporation was performed $250 \mathrm{mV}$ for $7 \mathrm{msec}$ (Electro Square Porator ECM830 with Safety Stand 630B and Electroporation Cuvettes Plus no $6404 \mathrm{~mm}$ GAP cuvettes; BTX, San Diego, USA). Cells were left to equilibrate for at least $10 \mathrm{~min}$, transferred into an Eppendorf tube and mixed with $500 \mu \mathrm{l}$ completed medium. From this, a suitable volume was transferred into a 24-well plate and incubated for indicated times at $37^{\circ} \mathrm{C}$ in a $5 \%$ $\mathrm{CO} 2$ humidified air atmosphere until analysis.

\section{Cell Cycle Analysis}

To confirm arrest of cells in the S-phase, cell cycle analysis was performed based on flow cytometric analysis of cell DNA content following cell staining with propidium iodide (Fig. 1). After synchronization treatment, the cells were washed two times with PBS to ensure removal of all dead cells, harvested and fixed. Fixation was achieved by incubating the cells in a $300 \mu \mathrm{lBS} / 700 \mu \mathrm{l}$ ethanol solution at $-20^{\circ} \mathrm{C}$ for at least $1 \mathrm{~h}$. After fixation the ethanol/cell solution was underlayered with $1 \mathrm{ml} \mathrm{FCS} \mathrm{before} \mathrm{being} \mathrm{spinned} \mathrm{down} \mathrm{and} \mathrm{resuspended}$ in $500 \mu \mathrm{l}$ (for $1 \cdot 10^{6}$ cells) PBS containing PI and RNase (930 $\mu \mathrm{l} \mathrm{PBS,} 50 \mu \mathrm{l} \mathrm{PI}(1 \mathrm{mg} / \mathrm{ml})$, and $20 \mu \mathrm{l}$ RNAse $(5 \mathrm{mg}$ / $\mathrm{ml})$ ). After 1 hour incubation at room temperature the cells were analyzed with a FACSCantoII cytometer (Becton and Dickinson, Mountain View, CA, USA) equipped with a $488 \mathrm{~nm} 20 \mathrm{~mW}$ Solid State diode laser and a $633 \mathrm{~nm}$ $20 \mathrm{~mW}$ HeNe laser. Ten thousand cells were recorded per sample, and cell cycle analysis of DNA profiles was performed using Gylchred software, available from Cytonet UK.

\section{Stimulation of NFKB}

Cells were incubated for $3 \mathrm{~h}$ with poly- or lipoplexes, after which the medium was replaced by $500 \mu \mathrm{l}$ complete
Fig. I Arrest of HeLa cells in S-phase by treatment with I5 $\mu \mathrm{M}$ aphidicolin.
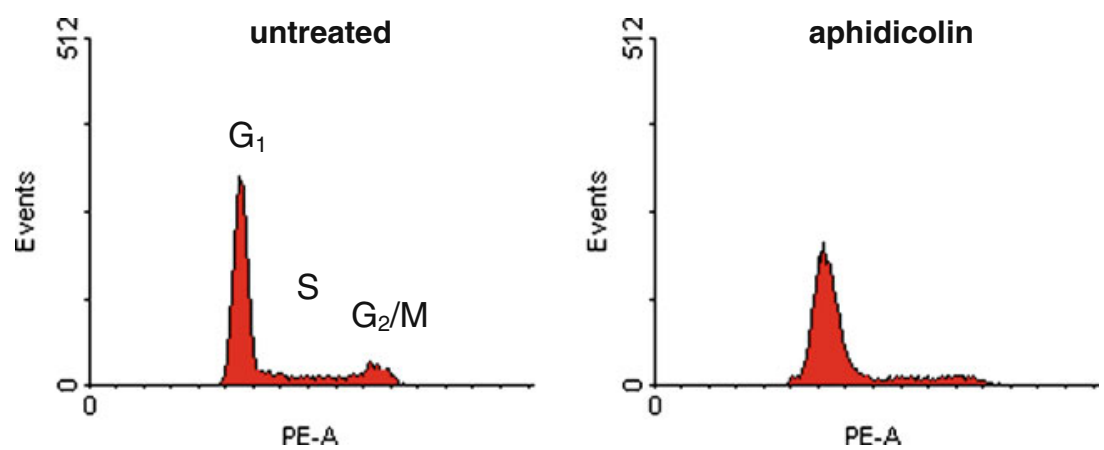
medium supplemented with $25 \mathrm{ng} / \mathrm{ml}$ TNF- $\alpha$. After another $3 \mathrm{~h}$ incubation, cells were harvested and analyzed.

\section{Flow Cytometry}

Forty eight hours after transfection, cells were washed, trypsinized and resuspended in DMEM supplemented with $10 \%$ FBS to inactivate the trypsin. Cells were transferred into round-bottom 96-well plates and centrifuged for $5 \mathrm{~min}$ at $250 \times \mathrm{g}$ at $4^{\circ} \mathrm{C}$. Medium was removed and cells were resuspended in $200 \mu \mathrm{l}$ phosphate-buffered albumin (PBA; $1 \%, \mathrm{w} / \mathrm{v}$ albumin in PBS). Immediately prior to measurement, $20 \mu \mathrm{l}$ of a PI solution $(10 \mu \mathrm{g} / \mathrm{ml}$ in water) was added for live/dead cell discrimination. Flow cytometric analysis was performed on a FACSCantoII (Becton and Dickinson, Mountain View, CA, USA) equipped with a $488 \mathrm{~nm}$ $20 \mathrm{~mW}$ Solid State diode laser and a $633 \mathrm{~nm} 20 \mathrm{~mW} \mathrm{HeNe}$ laser. A live gate was set on the viable cell population in FSC-SSG plot, and from this, the percentage of positive cells was obtained by setting a gate in the FL1-FL3 plot to exclude all PI-positive and FL1-negative cells. Ten thousand cells were recorded per sample, to determine EGFP expression (FITC-channel) and PI-staining (PE-channel).

\section{Quantification of Nuclear Localization by Cell Fractionation and Q-PCR}

Quantification of plasmid copies delivered to nuclei was performed based on a method developed by Cohen et al. (47). Transfection procedures were similar as described above, but were upscaled to T75 culture flasks per sample: $1.8 \cdot 10^{6}$ cells were seeded per flask, and transfections were performed at a dose of $18 \mu \mathrm{g}$ per flask.

\section{Isolation of Cell Nuclei}

Twenty four hours after transfection, cells were harvested, and nuclei were isolated by swelling in $1 \mathrm{ml}$ hypotonic buffer $(10 \mathrm{mM}$ PIPES pH 7.4, $1 \mathrm{mM}$ DTT, $2 \mathrm{mM} \mathrm{MgCl} 2,10 \mathrm{mM} \mathrm{KCl}$ ) for $25 \mathrm{~min}$ followed by lysis in a Dounce homogenizer (Wheaton, VWR International BV, Amsterdam, The Netherlands) with 50 strokes of the tight pestle. Cell lysates were mixed with equal volumes of 50\% iodixanol (Optiprep Density Gradient Medium; Sigma-Aldrich, St. Louis, USA) in isotonic buffer $\left(10 \mathrm{mM} \mathrm{Na} \mathrm{HPO}_{4}, 1 \mathrm{mM} \mathrm{MgCl}_{2}\right.$, $130 \mathrm{mM} \mathrm{KCl}, \mathrm{pH}$ 7.4). Single particle optical sensing (SPOS) was used to confirm that cells were lysed and nuclei were intact.

A three-step discontinuous iodixanol gradient was prepared by first underlaying $3 \mathrm{ml}$ of $30 \%$ and $35 \%$ iodixanol in isotonic buffer and then carefully adding the cell lysate (in 25\% iodixanol) on top. After spinning for
$40 \mathrm{~min}$ at $10,000 \times \mathrm{g}$ at $4^{\circ} \mathrm{C}$ in a swing-out rotor (Beckman OptimaTM LE-80 K Ultracentrifuge with SW41-TI rotor, Beckman Coulter B.V., Woerden, The Netherlands), nuclei were recovered from the $30 / 35 \%$ interface with a 18 -gauge needle (Sterican $18 \mathrm{G} \times 1$ 1/2"; B. Braun Melsungen AG, Melsungen, Germany).

\section{Total DNA Extraction}

Isolated nuclei were lysed by treatment with $0.5 \%$ SDS, $100 \mu \mathrm{g} / \mathrm{ml}$ proteinase $\mathrm{K}$ and $20 \mu \mathrm{g} / \mathrm{ml}$ RNase for $5 \mathrm{~h}$ at $50^{\circ} \mathrm{C}$. Total DNA was recovered by subsequent extractions with equal volumes of TE-saturated phenol $(1 \times)$ and phenol: chloroform:isoamyl alcohol 25:24:1 $(2 \times)$ followed by washes with water-saturated ether $(2 \times)$. DNA was precipitated from the final water phase with $1 / 10 \mathrm{~V}$ sodium acetate $(3 \mathrm{M}$, $\mathrm{pH}$ 5.2) and $2 \mathrm{~V}$ ice-cold $96 \%$ ethanol incubated overnight at $-20^{\circ} \mathrm{C}$. After washing the DNA pellet with $70 \%$ ethanol, the pellet was air-dried and dissolved in MilliQ-water. Samples were used directly or stored at $-20^{\circ} \mathrm{C}$.

\section{Quantification of Plasmid and Genomic Actin DNA Copies by $Q-P C R$}

Actin copies were quantified using Taqman Gene Expression Assay Hs03023880_gl (Applied Biosystems, Foster City, USA), which contains primers, and a FAM-labeled TaqMan MGB probe to amplify human genomic $\beta$-actin DNA. PGR reaction mixtures were prepared containing $5 \mu \mathrm{l}$ DNA $(2-2,000 \mathrm{fg}), 1 \mu \mathrm{l}$ Taqman gene Expression Assay, $10 \mu \mathrm{l} 2 \times$ TaqMan Universal PCR Master Mix (Applied Biosystems, Foster City, USA) and MilliQ-water added to a final volume of $20 \mu \mathrm{l}$. PCR was performed using a two-temperature thermal cycling program consisting of $15 \mathrm{~s}$ at $95^{\circ} \mathrm{C}$ and $60 \mathrm{~s}$ at $60^{\circ} \mathrm{C}$ for 40 cycles. A standard curve of plasmid pAct, which contains the human $\beta$-actin sequence (pCMV-Sport6 containing the complete CDS for Homo sapiens actin, beta, mRNA (cDNA clone MGG:5475 IMAGE:3451917); Invitrogen, Oregon, USA) was used to calibrate the PCR system.

Plasmid DNA was quantified with a SYBR Green assay using a three-temperature thermal cycling program consisting of $10 \mathrm{~s}$ at $95^{\circ} \mathrm{C}, 10 \mathrm{~s}$ at $61^{\circ} \mathrm{C}$ and $30 \mathrm{~s}$ at $72^{\circ} \mathrm{C}$ for 40 cycles. Primers were designed to specifically amplify a $116 \mathrm{bp}$ region from the ampicillin CDS using VectorNTI (Invitrogen) and Primer-BLAST (available from NCBI) software and are of the following sequence: forward 5'TCG-ATA-GTT-GGG-TGA-CTC-CG-3' and reverse 5'GAT-AAA-TCT-GGA-GGG-CGT-GA-3'. PGR reaction mixtures consisted of $5 \mu \mathrm{l}$ DNA (2-2,000 fg), $250 \mathrm{nM}$ forward primer, $250 \mathrm{nM}$ reverse primer, $10 \mu \mathrm{l}$ iQ SYBR Green Supermix (Bio-Rad, Hercules, USA) and MilliQwater added to a final volume of $20 \mu \mathrm{l}$. A standard curve of 
known amounts of plasmid pAct was used to calibrate the PCR system.

Since 2 actin copies are present per genome per cell, the number of plasmids per nucleus was calculated as \# plasmid copies/(\# actin copies/2).

\section{Experimental Setup and Statistical Analyses}

On each experimental day, three independent plasmid/ carrier preparations were made and tested on the same batch of cells.

\section{RESULTS}

\section{Design and Cloning of Plasmid Constructs}

To study and compare effects of various DTSs on gene delivery efficiency, DTSs were identified from literature $(35,36,42,44,48)$, and a range of plasmid constructs were prepared as described in the Materials and Methods section. The SV40 origin/promoter sequence was excised from pCMV/EGFP to obtain the control plasmid pCMV/ EGFP_noDTS. Subsequently, the SV40 72-bp repeat, a repetition of 2, 3 or $5 \mathrm{NF \kappa B}$ consensus binding sites, or a glucocorticoid responsive element was inserted at the position where the SV40 ori/promoter sequence previously was located (Fig. 2). Successful modifications were confirmed by sequencing.

\section{Effect of DNA Nuclear Targeting Sequences on Transfection Efficiency}

HeLa cells were transfected with plasmids containing the complete SV40 promoter/origin region, plasmids from which this complete region was deleted and plasmids in which a DTS region was inserted: 72-bp enhancer region of SV40, 2 $3-5 \times$ NFkB binding sites or a glucocorticoid responsive element (GRE). Gene expression was analyzed $6 \mathrm{~h}$ after the start of transfection to minimize effects of mitosis. As shown in Fig. 3, no significant differences between the plasmid lacking a DTS sequence and any of the constructs containing a DTS were observed. This means that presence or absence of a DTS did not affect the number of cells that is successfully transfected. Since it is possible that the DTS did have an effect on the amount of transgenes expressed per successfully transfected cell, we also looked at the mean fluorescence intensity (MFI), but no differences were observed (data not shown). Next, we tested if TNF- $\alpha$ stimulation could induce uptake of the NFkB-based constructs. Treatment with TNF$\alpha$ induces activation of NFkB leading to nuclear translocation of NFкB. It is therefore expected that plasmids containing $\mathrm{NF \kappa B}$ binding sites are preferentially shuttled into the nucleus. Figure $3 \mathrm{~b}$ shows that transfection efficiency for the NFkB-plasmids was indeed enhanced (again, similar trends were observed when analyzing MFI). However, transfection efficiencies were increased to a similar extent for all other constructs tested. Stimulation of gene expression was similar for plasmids containing the full SV40 promoter/

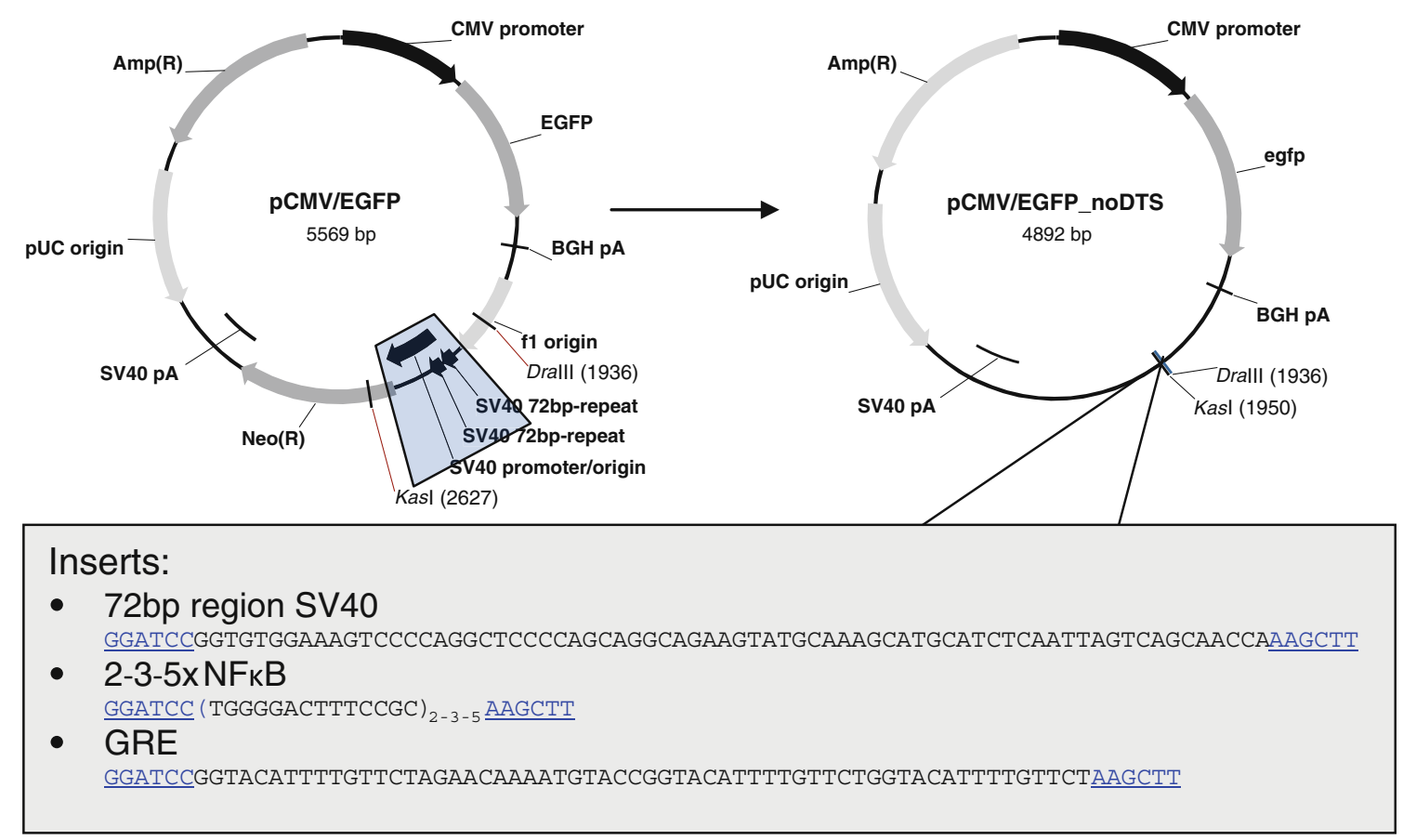

Fig. 2 Design and cloning of plasmid constructs. 

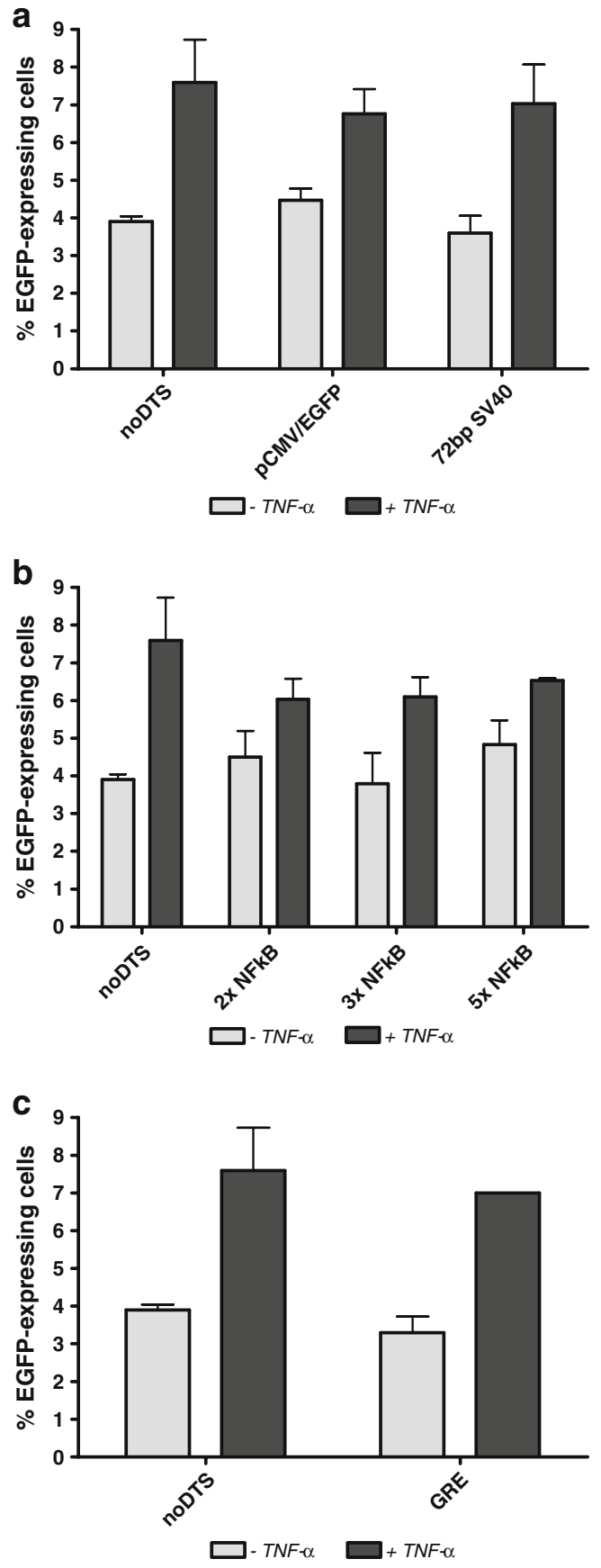

Fig. 3 The effect of various DTS on transfection efficiency. \% EGFPexpressing cells after transfection with SV40-based DTS (a), NFKB DTS (b) and a GRE DTS (c). HeLa cells were transfected with the indicated plasmids and lipofectamine for $4 \mathrm{~h}$ in the presence of serum, washed and analyzed $6 \mathrm{~h}$ after the onset of transfection. Cells were non-stimulated (light grey bars) or stimulated by incubation with $25 \mathrm{ng} / \mathrm{ml}$ TNF-a during time of transfection (dark grey bars). Data are presented as mean \pm SD $(n=3)$. One-way ANOVA followed by post hoc analysis with Bonferroni correction was performed on the expression data of each plasmid. None of the plasmids differed significantly from plasmid noDTS either in the presence or absence of TNF-a. ori region, the minimized 72-bp SV40 region or plasmids from which the entire SV40 regulatory region was removed (Fig. 3a). Lastly, a plasmid from which the SV40 region was replaced by a glucocorticoid responsive element (GRE) responded similarly to TNF- $\alpha$ treatment as the plasmids containing several NFkB binding sites (Fig. 3c).

These results show that the stimulation induced by TNF- $\alpha$ was unspecific and is most likely related to upregulation of transcriptional processes. The plasmids tested were all under transcriptional control of the $\mathrm{CMV}$-promoter, and this promoter contains three NFkB binding sites, which may explain the transcriptional activation upon TNF- $\alpha$ stimulation. Interestingly, despite the presence of these NFKB sites, the CMV-promoter itself was previously described not to be involved in nuclear import processes $(36,41)$.

Since we did not manage to achieve DTS-mediated increase in transfection efficiency with any of the constructs tested, we continued to examine the parameters that could be critical in obtaining sequence-specific nuclear uptake. For this, we selected the pCMV/EGFP (DTS) and pCMV/ EGFP_noDTS (noDTS) for proof-of-principle studies.

\section{Effect of Delivery Strategy on DTS Effect}

The suggested mechanism of DTS-induced nuclear uptake is sequence-specific binding of NLS-containing transcription factors to plasmid DNA that is delivered into the cytosol, followed by import of the formed TF/plasmid complexes into the nucleus. This implies that the plasmid is delivered into the cytosol and that the DNA is available for interaction with those proteins. It is therefore expected that escape from vesicles and (partial) dissociation from the carrier is essential for the DTS effect to occur. To test if the type of delivery affected occurrence of the DTS effect, three methods to introduce plasmid into cells were tested. Lipofectamine was used as a transfection reagent which has been described to release DNA prior to nuclear uptake and transcription (45). In contrast, $22 \mathrm{kDa}$ linear pEI is thought to deliver DNA into nuclei as intact complexes $(41,46,49)$ and has even been described to allow transcription to occur while still bound to the plasmid (16). Electroporation was used to introduce naked DNA directly into the cytosol, bypassing vesicular uptake and release and unpackaging of complexes. Figure 4 shows that regardless of the delivery strategy chosen, no differences in transgene expression efficiency were observed for plasmids containing or lacking a DTS. Neither the $\%$ of transfected cells nor the mean EGFP expression per cell differed significantly for plasmids containing or lacking the DTS.

\section{Dependency of the DTS Effect on Mitosis}

In the previous experiments, transfections were performed in dividing cells. Possibly, benefits in increased active 
a $\%$ Transgene expressing cells
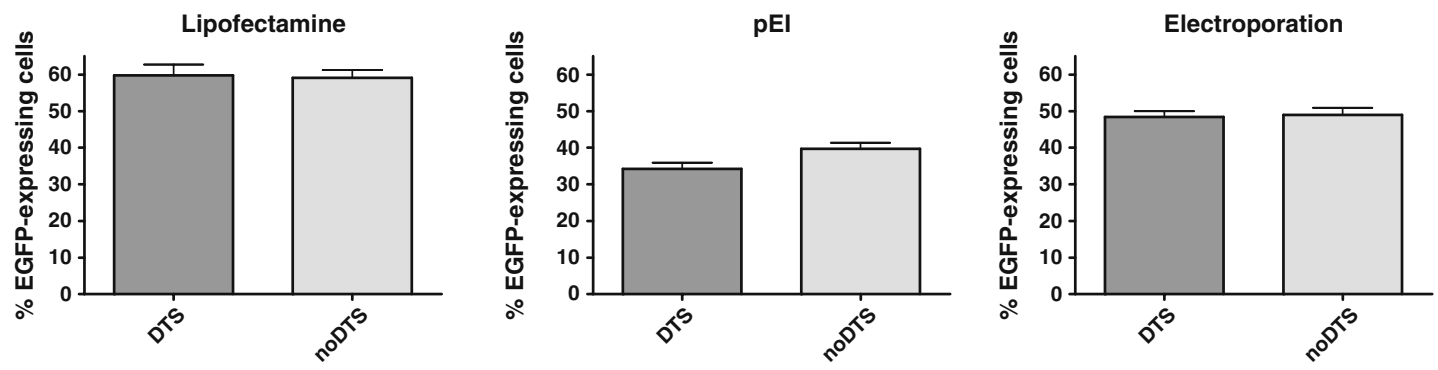

b Mean expression per cell
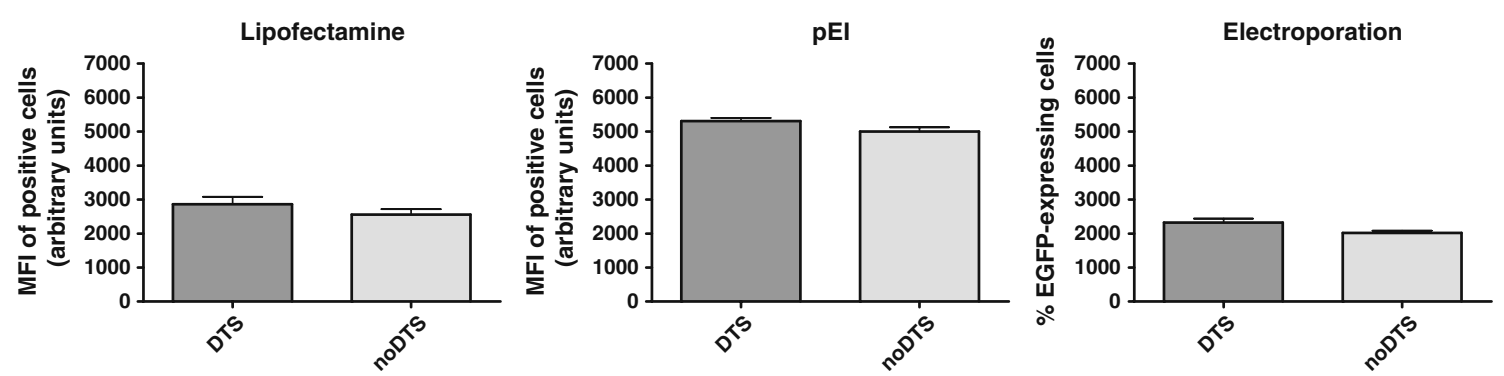

Fig. 4 Dependency of the DTS effect on delivery strategies. \% of EGFP-expressing cells (a) and mean expression per cell (b) after transfection with lipofectamine (left), $22 \mathrm{kDa}$ linear pEl (middle) or after electroporation (right) of plasmids with DTS (pCMV/EGFP; dark grey bar) versus plasmids without DTS (pCMV/EGFP_noDTS; light grey bar). Cells were transfected at a dose of I $\mu \mathrm{g}$ DNA/well in a 24-well plate with lipofectamine or pEI for $4 \mathrm{~h}$ in the presence of serum, washed and analyzed after $48 \mathrm{~h}$ or electroporated at a dose of $2 \mu \mathrm{g} / 2.25 \cdot 10^{5}$ cells and analyzed after $24 \mathrm{~h}$. Data are represented as mean $\pm \mathrm{SD}$ of three independent measurements. MFI: mean fluorescence intensity.

uptake are outweighed by bulk access to the nucleus when the nuclear envelope is temporarily broken down at the time of mitosis. The shortest incubation time tested was $6 \mathrm{~h}$, which is well below the cycling time of HeLa cells. Nevertheless, due to the asynchronous nature of cultured cells, a fraction of cells will still be undergoing mitosis within this interval. To minimize this fraction even further, cells were incubated with aphidicolin, a reagent that arrests cells in S-phase by interfering at the level of DNA synthesis and with relatively mild cytotoxicity (50). Results obtained in HeLa cells after lipofectamine-based transfections of plasmids containing or lacking the SV40 DTS are shown in Fig. 5 (left panel). Again, no significant difference between the two plasmid constructs was observed, regardless of incubation time, and, most importantly, no effect was observed in non-dividing cells. Similar results were obtained in a second human cell line, A431 (Fig. 5, right panel).

\section{DTS Effect and Amount of Plasmids Delivered into the Cytosol}

Dean et al. hypothesized that a DTS effect may be overshadowed when using large amounts of plasmids as this may lead to some plasmids being taken up into the nucleus irrespective of any DTS effect (12). In support of this hypothesis, Utvik et al. (51) have reported a threshold level of $10^{6}$ plasmid copies/cell above which nuclear uptake occurs in the absence of cell division and in the absence of any active nuclear targeting strategy.

In our transfection experiments a dose of $1 \mu \mathrm{g}$ DNA per well of a 24-well plate is applied, which corresponds to roughly $2 \cdot 10^{6}$ plasmids/cell. It is not expected that $100 \%$ of the applied dose is taken up by cells; therefore, it is unlikely that under the conditions used the threshold reported by Utvik et al. (51) is exceeded. Nevertheless, it is unknown if the reported threshold applies to different cell types. Therefore, to fully exclude the phenomenon of mass action, an experiment was performed in which the numbers of plasmids dosed per cell were decreased and both the actual amount delivered into the cells and the transgene expression were monitored. In the first experiment, HeLa cells were electroporated with various amounts of plasmids with or without DTS, and gene expression was measured $24 \mathrm{~h}$ after electroporation (Fig. 6a). Transfection efficiency was similar for the two plasmid constructs at all amounts tested. Up to a dose of $1 \mu \mathrm{g}$, each two-fold increase in applied dose resulted in a two-fold increase in the \% successfully transfected cells. At doses exceeding $1 \mu \mathrm{g}$, a saturation effect was observed, and a maximum number of transgene-expressing cells of approximately 50\% was reached. When looking at the mean expression per cell, 

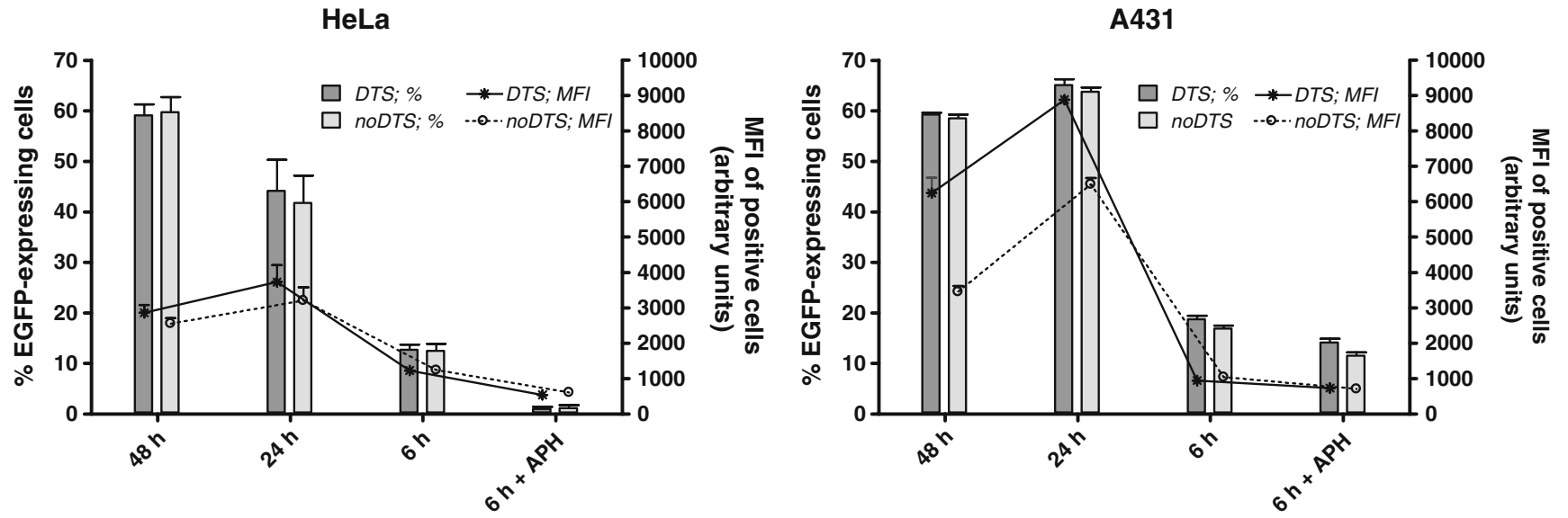

Fig. 5 Dependency of the DTS effect on mitosis. \% of EGFP-expressing cells (bars; left y-axis) and MFI of positive cells (lines; right y-axis) after transfection of HeLa cells (left panel) or A43I cells (right panel) with plasmids with DTS (pCMV/EGFP; dark grey bar and asterix) versus plasmids without DTS (pCMV/ EGFP_noDTS; light grey bar and open circle). Cells were transfected at a dose of I $\mu \mathrm{g}$ DNA/well in a 24-well plate with lipofectamine for $4 \mathrm{~h}$ in the presence of serum, washed and analyzed at the indicated timepoints after onset of transfection. As a model for non-dividing cells, cells were arrested at the $\mathrm{S}$-phase by treatment with $15 \mu \mathrm{M}$ aphidicolin starting $24 \mathrm{~h}$ prior to transfection and continuously throughout the experiment. Data are represented as mean $\pm \mathrm{SD}$ of three independent measurements.

again a dose-response relation is observed. However, the expression per cell increases only by a factor two upon a sixteen-fold increase in dose. This shows that once a cell is successfully transfected, the number of plasmids transfected is not an important parameter for overall transfection efficiency. Possibly, transcription and/or translation processes become rate-limiting at this stage. A second experiment was performed in which cells were treated similarly, but gene expression was measured $4 \mathrm{~h}$ after electroporation to minimize effects of cell division (Fig. 6b). Since the proportion of cells passing through mitosis in the course of the experiment is largely reduced, DTS-mediated nuclear import was expected to become more apparent. The results show that very few cells $(<3 \%)$ were transfected, independent of the presence of the DTS. This indicates that the DTS was inefficient in mediating active nuclear uptake and subsequent transgene expression in the large fraction of non-dividing cells within the total cell population. Similar to the trends observed after $24 \mathrm{~h}$ incubation, DNA dose predominantly affected the $\%$ of transfected cells and, to a much lesser extent, the expression per cell.

In these experiments, the highest plasmid dose used was $2 \mu \mathrm{g}$ DNA $/ 2.25 \cdot 10^{5}$ cells, which corresponds to delivery of maximally $1.5 \cdot 10^{6}$ plasmids/cell. This dose is close to the critical dose of $1 \cdot 10^{6}$ described by Utvik et al., but is most likely a gross overestimation of the actual amount of plasmids delivered. To check this, how much of the applied dose was actually delivered into the cells after electroporation was quantified by measuring plasmid copy numbers relative to actin copy numbers by Q-PCR on cell lysates. After electroporation of $1.8 \mu \mathrm{g} / 2.25 \cdot 10^{5}$ cells (corresponding to $1.3 \cdot 10^{6}$ plasmids/cell), an average plas- mid copy numbers/cell of $1.5( \pm 0.6) \cdot 10^{3}$ was detected. This confirms that the number of plasmids that reached the cell cytosol in these experiments was well below the levels described by Utvik et al., making it unlikely that the DTS effect was masked by unspecific nuclear uptake due to overloading of the cytosol.

\section{DTS Effect Observations at Level of Localization or Expression}

The efficiency of nuclear delivery for plasmids containing or lacking a DTS was evaluated by isolating nuclei from transfected cells and quantification of plasmid copies by QPCR. The number of genomic actin copies was determined for use as an internal standard representing the number of cells (cell nuclei). Hypotonic swelling followed by Dounce homogenization rather than detergent-based cell lysis was used for cell fractionation, as this was previously described to yield a pure nuclear fraction with minimal contamination of cytoplasmic components (47). First, Q-PGR was performed on total cell lysates to determine the efficiency of uptake into cells. After incubation of cells with complexes for $4 \mathrm{~h}$, and an additional hour in the absence of complexes, cells were harvested and analyzed. As shown in Table II, transfection of pCMV/EGFP with lipofectamine resulted in $5.4( \pm 1.8) \cdot 10^{2}$ copies per cell in dividing cells (versus $3.4( \pm 1.7) \cdot 10^{2}$ for pCMV/EGFP_noDTS; difference is not significant). This number remained constant up to $24 \mathrm{~h}$ after transfection, indicating that little intracellular elimination occurred. Similarly, Ruponen et al. (52) found little elimination of plasmid DNA within $24 \mathrm{~h}$ after transfection with cationic liposomes. 

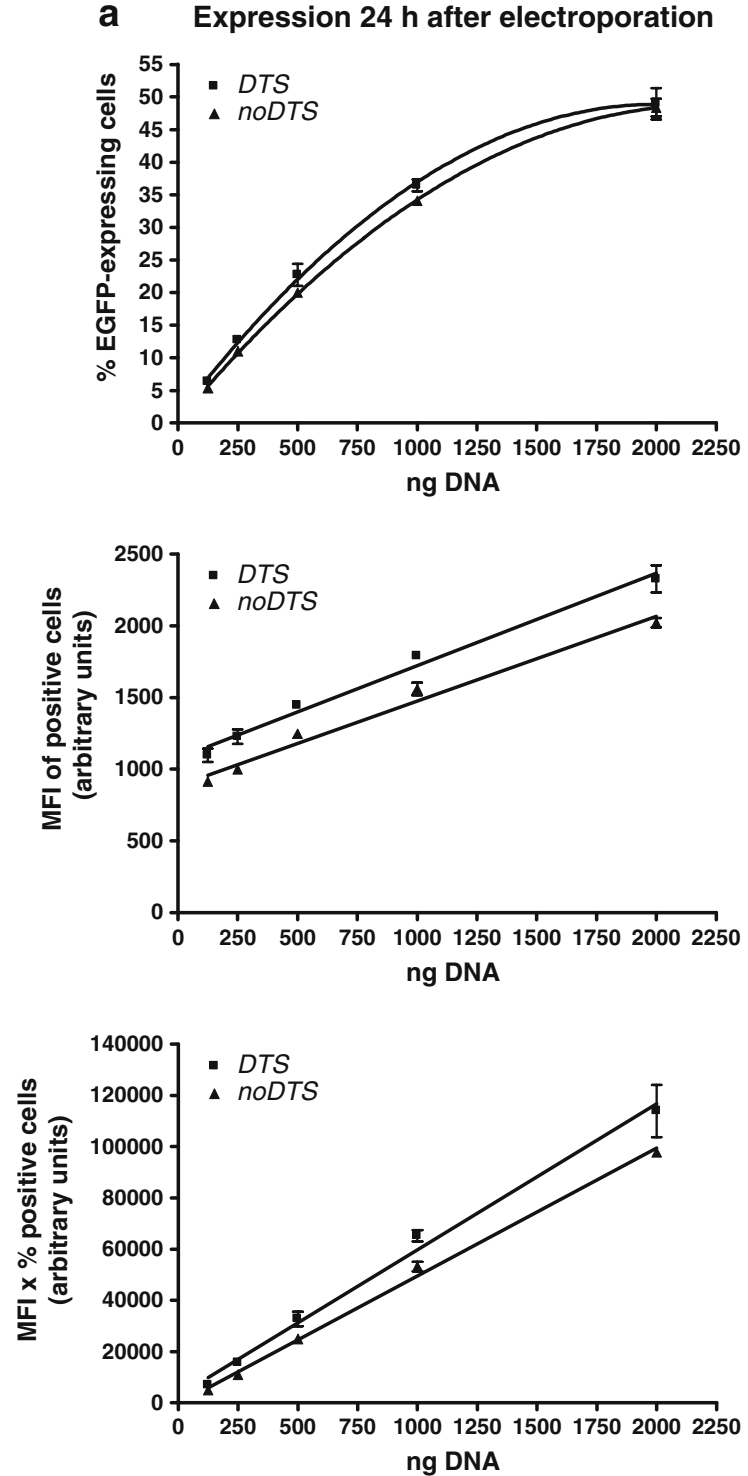

b Expression $4 \mathrm{~h}$ after electroporation
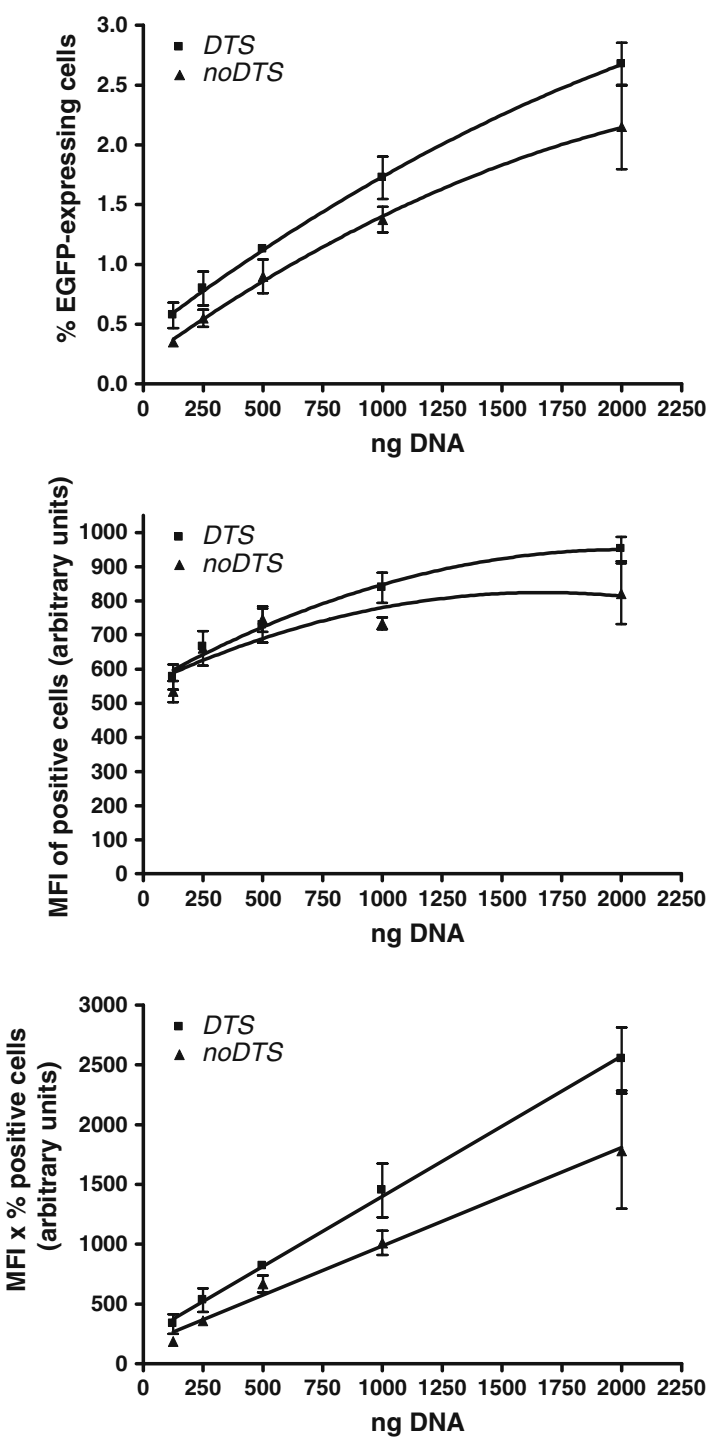

Fig. 6 Dose-dependent gene expression upon electroporation. HeLa cells were electroporated with varying doses of plasmids containing or lacking a DTS and analyzed for EGFP expression by flow cytometry either $24 \mathrm{~h} \mathrm{(a)} \mathrm{or} 4 \mathrm{~h}(\mathbf{b})$ after electroporation. Gene expression drops with decreasing plasmid amounts regardless of the presence or absence of a DTS.

Next, nuclei were isolated from transfected cells, and plasmid copy numbers/nucleus were determined (Table II). The number of plasmids per nucleus $24 \mathrm{~h}$ after transfection was $1.8( \pm 0.8) \cdot 10^{2}$ (versus $2.4( \pm 1.6) \cdot 10^{2}$ for $\mathrm{pCMV} /$ EGFP_noDTS; difference is not significant), corresponding to $\sim 40 \%$ of total cellular plasmid DNA. During the $24 \mathrm{~h}$ incubation, cells will have undergone at least one mitotic event during which plasmids gain bulk access into the nuclei, which may explain the high $\%$ found in nuclei. The situation in non-dividing cells was rather different. Twenty four hours after transfection of aphidicolin-arrested cells, $1.7( \pm 0.6) \cdot 10^{3}$ plasmid copies were detected per cell (compared to 5.4 \pm $1.8) \cdot 10^{3}$ for pCMV/EGFP_noDTS; difference is not signif- icant). Treatment of cells with aphidicolin has previously been described not to affect the rate of uptake of lipid/DNA complexes (53). The increased number of copies detected per cell as compared to dividing cells probably simply reflects the lower number of cells present in the absence of division. More importantly, the number of plasmid copies detected per nucleus was decreased to $2 \%-4 \%$ of total cellular plasmid DNA. This confirms that in the absence of mitosis, transport of DNA into the nucleus is severely diminished (although not completely abolished). The difference between copy numbers detected per nucleus after transfection with plasmids with or without DTS was not significant (7.5 $( \pm 2.7) \cdot 10^{1}$ versus $\left.3.4( \pm 1.1) \cdot 10^{1}\right)$. 
Table II Cellular and Nuclear Delivery of Plasmids with and without DTS in Dividing and Aphidicolin-Arrested Cells. The Number of Plasmid Copies per Cell or per Nucleus was Determined after Transfection with $22 \mathrm{kDa}$ Linear pEl or Lipofectamine. Cells were Transfected at a Dose of I8 $\mu \mathrm{g}$ DNA/T75flask (or $2.3 \mu \mathrm{g} /$ well in 6-well Format) with Lipofectamine or pEl for $4 \mathrm{~h}$ in the Presence of Serum, Washed and Analyzed after $24 \mathrm{~h}$ (or $5 \mathrm{~h}$ ). As a Model for Non-dividing Cells, Cells were Arrested at the S-phase by Treatment with $15 \mu \mathrm{M}$ Aphidicolin Starting $24 \mathrm{~h}$ Prior to Transfection and Continuously throughout the Experiment. Data are Represented as Mean \pm SD of Three Independent Measurements

\begin{tabular}{|c|c|c|c|c|c|}
\hline & & \multicolumn{2}{|l|}{ I-pEl } & \multicolumn{2}{|l|}{ Lipofectamine } \\
\hline & & + DTS & -DTS & + DTS & -DTS \\
\hline \multicolumn{6}{|c|}{ Dividing cells } \\
\hline $4+I h$ & \# plasmids/cell & $2.7 \pm 0.8 \times 10^{4}$ & $2.7 \pm 1.3 \times 10^{4}$ & $5.4 \pm 1.8 \times 10^{2}$ & $3.4 \pm 1.7 \times 10^{2}$ \\
\hline $24 \mathrm{~h}$ & \# plasmids/cell (C) & $1.4 \pm 0.2 \times 10^{4}$ & $1.9 \pm 0.5 \times 10^{4}$ & $4.9 \pm 2.8 \times 10^{2}$ & $2.8 \pm 0.9 \times 10^{2}$ \\
\hline $24 \mathrm{~h}$ & \# plasmids/nucleus ( $\mathrm{N}$ ) & $2.1 \pm 0.3 \times 10^{4}$ & $8.0 \pm 6.2 \times 10^{4}$ & $1.8 \pm 0.8 \times 10^{2}$ & $2.4 \pm 1.6 \times 10^{2}$ \\
\hline \multicolumn{6}{|c|}{ Aphidicolin-arrested cells } \\
\hline $24 \mathrm{~h}$ & \# plasmids/cell (C) & $9.8 \pm 3.9 \times 10^{4}$ & $2.3 \pm 1.3 \times 10^{5}$ & $1.7 \pm 0.6 \times 10^{3}$ & $5.4 \pm 1.8 \times 10^{2}$ \\
\hline $24 \mathrm{~h}$ & \# plasmids/nucleus $(\mathrm{N})$ & $7.4 \pm 5.3 \times 10^{4}$ & $1.3 \pm 0.2 \times 10^{5}$ & $7.5 \pm 2.7 \times 10^{1}$ & $3.4 \pm 1.1 \times 10^{1}$ \\
\hline
\end{tabular}

When comparing pEI and lipofectamine, large differences in detected copy numbers were observed. At times of 5-24 $\mathrm{h}$ after the start of transfection, roughly $2 \cdot 10^{4}$ plasmids were detected per cell in dividing cells when pEI was used as delivery agent. This is two orders of magnitude more than observed for lipofectamine. Again, copy numbers per cell were increased in aphidicolin-arrested cells. While collecting nuclei of pEI-transfected cells after ultracentrifugation through a discontinuous iodixanol gradient, we noticed the presence of aggregates at the 30/35\% interface which we did not observe during processing of lipofectamine-transfected cells. This is probably due to adherence of extranuclear plasmid DNA (-complexes) to the nuclei followed by aggregation and indicates that in our hands the method failed to yield pure nuclei devoid of extranuclear plasmid (-complexes) in case of pEItransfected cells. Analysis of the nuclear fractions showed that nuclear copy numbers did not differ from- or even outnumbered- total cellular copy numbers, which further supports our assumption that we failed to isolate clean nuclei. At the time of this writing efforts to further optimize and validate the method were still ongoing. Results obtained for pEI-based delivery therefore remain elusive. Nevertheless, in the experiments performed with lipofectamine no significant enhancement of plasmid nuclear localization that could be ascribed to the DTS effect could be detected.

\section{DISCUSSION}

In this paper, the relevance of DNA nuclear Targeting Sequences for improving efficiency of non-viral gene delivery was evaluated. Several DTSs were identified from literature and cloned downstream of an EGFP coding sequence that was under the control of the GMV-promoter. It was shown that insertion of either the full-length SV40 DTS (372 bp promoter/origin region), the partial SV40 DTS (72-bp enhancer region), repetitive NFKB binding sites or a glucocorticoid responsive element did not increase transgene expression. Additionally, preliminary findings showed that cloning of multiple repeats of the SV40 DTS had no beneficial effect on transfection efficiency (data not shown). It was shown that expression levels could be augmented by activation of the NFkB pathway through TNF- $\alpha$ stimulation. However, this effect was not restricted to plasmids containing $\mathrm{NF \kappa B}$ inserts, but also observed to a similar extent for all the other plasmids tested. This indicates that the effect is more likely related to unspecific transcriptional upregulation rather than NFKB specific nuclear import. In the plasmids used in this study, transcription is driven by the GMV promoter, which contains three NFKB binding sites and could therefore be upregulated by $\mathrm{TNF}-\alpha$-induced $\mathrm{NF \kappa B}$ activation. Interestingly, these sites seem to have no role in nuclear targeting, as Dean et al. (36) showed unability of the GMV promoter to direct nuclear localization of plasmid after cytoplasmic microinjection. The presence of $\mathrm{NF \kappa B}$ sites and their apparent unability to function as DTS remains unaddressed in his paper. In two papers by Gonçalves et al. and Breuzard et al., the importance of spacing between transcription factor binding sites is addressed, and it is suggested that the separation between the individual NFKB sites (142 and $152 \mathrm{bp}$ ) within the $\mathrm{CMV}$-promoter are not optimal to mediate NFKB-mediated nuclear import, but would be able to induce transcriptional enhancement $(41,54)$.

It was shown that the presence of the full-length SV40 DTS did not enhance transfection efficiency regardless of mitotic activity of cells. We aimed to compare three 
delivery methods to gain insight into whether the DTS is available for interaction with transcription factors after delivery into the cell. Contrary to the situation after electroporation, after transfection with lipids or polymers the DNA is present in a condensed form, and we hypothesized that this might interfere with binding of transcription factors. However, no DTS effect was observed for any of the delivery methods chosen (condensed/notcondensed). Dose-response experiments excluded the possibility that relatively small increments in specific nuclear uptake were outweighed by overloading the cytoplasm with plasmid DNA, which could potentially lead to unspecific nuclear uptake. Finally, it was evaluated whether effects of DTS could be detected at the level of translocation rather than expression. Results from quantitative PCR on nuclear fractions indicate that nuclear localization of plasmids was not facilitated by the presence of the full-length SV40 DTS.

Overall, the beneficial effects of DTS on transfection efficiency were much less than we expected based on findings from literature. Prasad et al. (55) also question the effect of an SV40 DTS on transfection efficiency of CMVplasmids. In their study, constructs with no SV40 DTS, the complete SV40 DTS or the 72-bp repeat were used to perform transient gene expression assays in various cell types. It was observed that gene expression from DTScontaining plasmids compared to expression from plasmids lacking a DTS varied with cell type and plasmid backbone used. In support of our data, they did not observe any beneficial effects in HeLa-cells. The authors conclude that effects of the SV40 DTS on overall gene expression are only weakly dependent on facilitated nuclear import. Other factors governing overall transfection efficiency would be enhancement of transcription and replication of plasmids containing the SV40 origin of replication in SV40transformed cells such as COS-7. Unfortunately, no data regarding nuclear localization efficiency are included; therefore, these statements remain speculative.

In our study, we attempted to study the effect of DTS at the level of nuclear localization efficiency by performing quantitative PCR on isolated nuclei. Studies presenting data on quantification of intranuclear plasmids are still limited, although important progress has been made in the past years. Various methods have been described, including microscopic analysis based on FISH detection $(35,56)$, sometimes combined with FRET or FRAP effects (41). Drawbacks of these techniques are the need for fluorescent labeling and consequent artifacts (especially if DNA is labeled prior to transfection (57)), detection limits, resolving power to discriminate internal from adhered DNA and poor statistical power related to the low number of cells analyzed. Alternatively, methods based on cell fractionation and quantification of DNA in the nuclear fraction have been described. Isolated nuclei were previously analyzed by flow cytometry $(14,58,59)$, Southern blotting (60) or quantitative PCR $(17,47,60,61)$. Analysis by flow cytometry seems the fastest and simplest option, but requires fluorescent labeling of DNA and is complicated by low yields of isolated nuclei (personal communication) and leakage of compounds out of the nuclei (14). Q-PCR offers a sensitive and quantitative analysis on non-modified plasmid DNA and was chosen here. A general concern in cell fractionation is cross-contamination among fractions, in our case contamination of the nuclear fractions with extranuclear DNA (complexes). The majority of cell fractionations is performed after cell lysis with detergents (14,17,58-61). Cohen et al. (47) showed that detergent-lysis induces aggregation of nuclei and adsorption of DNA (complexes) to the outer membrane of the cell nuclei. Moreover, they show that this plaque could not be sufficiently removed by treatment with competitive agents (pASPA, DNA) or restriction enzymes. They developed an alternative method where cells are lysed by hypotonic swelling followed by Dounce homogenization, which is described to yield clean nuclei largely free from plaque.

Using this method, we found nuclear plasmid copy numbers of $1.8( \pm 0.8) \cdot 10^{2}$ and $2.4( \pm 1.6) \cdot 10^{2}$ after lipofectamine-based transfection of dividing cells with pCMV/EGFP and pCMV/EGFP_noDTS, respectively. We used a dose of $18 \mu \mathrm{g}$ DNA/T75 flask seeded with $1.8 \cdot 10^{6}$ cells, and taking into account the doubling time of cells, this corresponds to a dose of roughly $8 \cdot 10^{5}$ plasmid copies/cell. In comparison, Cohen et al. (47) detected approximately $1 \cdot 10^{3}$ plasmid copies per nucleus after transfection with either linear pEI or lipofectamine at a dose of $1 \cdot 10^{5}$ plasmid copies per cell. Tachibana et al. (60) report nuclear delivery of $1 \cdot 10^{4}$ plasmid copies per nucleus after transfection with cationic liposomes and a dose of $20 \mu \mathrm{g} / 5 \cdot 10^{6}$ cells, which is slightly less than doses used by us. Hama et al. (61) recovered $1.7 \cdot 10^{4}$ plasmid copies per nucleus from cells transfected with lipofectamine at a dose of $2.5 \mu \mathrm{g} / 2.5 \cdot 10^{5}$ cells. The latter two studies used detergent-lysis, which could explain the higher copy numbers found. James and Giorgio (58) used flow cytometric analysis of fluorescence in isolated nuclei and found 1,250 pCMV-plasmids per nucleus in Hela cells $4 \mathrm{~h}$ posttransfection with cationic liposomes (dose $1.25 \mu \mathrm{g} / 2 \cdot 10^{5}$ cells). Breuzard et al. (41), who used microscopic analysis for quantification of nuclear delivery, report lower numbers: approximately 368 copies/nucleus in cells transfected with pCMV/luc complexed with linear pEI (dose $0.5 \mu \mathrm{g} / 1 \cdot 10^{4}$ cells). These data show that copy numbers found by us after transfection in dividing cells are within the expected range (at the lower end). In non-dividing cells, we detected 7.5 $( \pm 2.7) \cdot 10^{1}$ versus $3.4( \pm 1.1) \cdot 10^{1}$ plasmid copies/nucleus for pCMV/EGFP and pCMV/EGFP_noDTS, respectively. To our knowledge, no previous attempts have been 
described to quantify nuclear uptake in aphidicolin-arrested cells. The difference in plasmid copy numbers/nucleus resulting from transfection of either dividing or nondividing cells with plasmid containing or lacking the SV40 DTS was not significant. Previous studies investigating the role of DTS in gene delivery relied on microscopic techniques to evaluate nuclear uptake. Discrepancies between findings regarding the effect of DTS on nuclear localization might be inherent to differences in methods chosen. At this stage, the presence of extranuclear plaque cannot be fully excluded, and this could obscure subtle differences in intranuclear copy numbers. Additionally, it should be mentioned that the method used in this study is based on batch analysis of DNA in pooled nuclear fractions, leaving heterogeneity among cells within a population unconsidered. Using microscopic techniques offers the ability to study individual cells and take into account heterogeneity by quantifying both the number of plasmidpositive nuclei and ranking the signal within these nuclei.

Nevertheless, even if small increments in nuclear uptake were overlooked by us, this would not change the observation that transgene expression was unaffected by the presence of a DTS. We conclude that the DTS effect may occur at the level of nuclear import but is obscured by effects on any of the other steps involved (i.e. transcription, translation). In our study, plasmids in which transcription was controlled by the strong CMV-promoter were used to ensure detectable expression levels in poorly transfectable non-dividing cells. We propose the following hypothesis, which is schematically presented in Fig. 7. When using a strong promoter, the bottleneck is at the (post-)transcriptional level, and increments in pre-transcriptional processes, including nuclear uptake, do not affect overall gene expression levels. In contrast, when using a weak promoter, the transcription machinery is not saturated, and increases in nuclear delivery of plasmids lead to increased transcription and translation (until translation is saturated), hence increased transgene expression. In support of this hypothesis, a threshold for nuclear delivery of plasmids has been described above which additional plasmids no longer result in increased expression $(47,60)$. This means that above this threshold, processes following nuclear uptake become the limiting factor, possibly subnuclear disposition or translation (17).

The presented hypothesis also explains discrepancies between our results and findings by others. For example, Gonçalves et al. (54) and Breuzard et al. (41) describe the optimization of an extended NFאB DNA binding site and show that insertion of these NFкB binding sites into pTal, a plasmid in which luciferase is driven by a minimal promoter, increased transgene expression levels 1,600-fold and an additional 8-fold after stimulation with TNF- $\alpha$ as compared to the control plasmid. Expression levels obtained with the modified plasmid reached similar levels as an unrelated plasmid in which luciferase was under control of the strong CMV-promoter. When looking at nuclear delivery, the NFאB-modified plasmid was reported to deliver 6-fold more copies than the control vector, and 4fold more than the CMV-luc plasmid (5 h after transfection of TNF- $\alpha$ stimulated HeLa cells). No constructs in which NFкB binding sites were combined with the CMVpromoter were tested. Nevertheless, the observation that much less CMV-luc is delivered into nuclei than the NFкBmodified plasmid, although expression levels are similar, supports our findings/hypothesis.

Similarly, Mesika et al. (42) showed a 12-fold increase in transfection efficiency after insertion of repetitive NFкB binding sites into a construct in which expression is under the control of the SV40 promoter, which is considerably weaker than the CMV promoter (62).

In the case of Thanaketpaisarn et al. (63), increased expression is in fact observed upon insertion of NFKB binding sites into a CMV-driven plasmid. Possibly, this is due to the position of the NFkB-sites within the plasmid. DTSs can elicit two effects: one is promoting nuclear uptake and is thought to be position-independent, whereas the other one is transcriptional enhancement which is position-dependent (41). Thanaketpaisarn et al. have cloned the NFkB-sites directly
Fig. 7 Schematic presentation of hypothesized bottlenecks (black arrows) for transgene expression of plasmid driven by a strong or weak promoter.

Cellular uptake Intracellular transport Nuclear uptake Transcription Translation
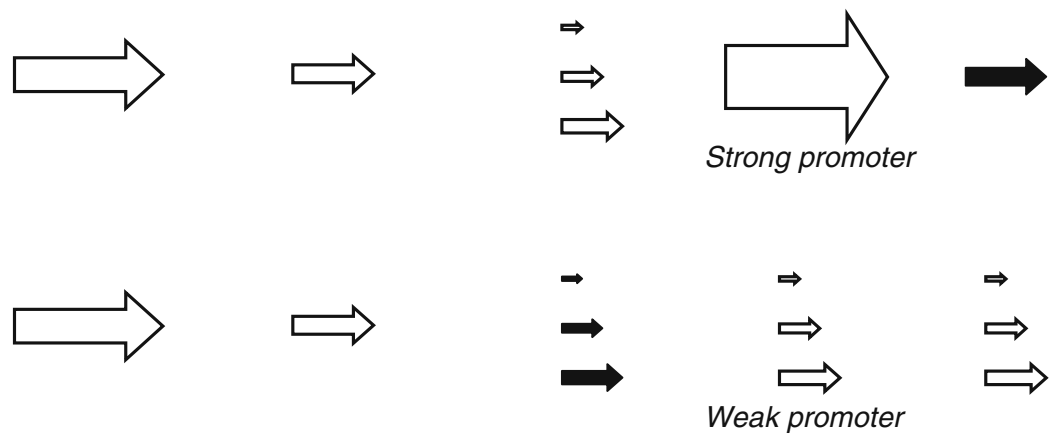

Weak promoter 
upstream the GMV-promoter, and they may therefore be involved in direct enhancement of CMV-driven transcription, whereas in our constructs the DTSs were cloned downstream of the coding sequence. Indeed, the authors mention in their discussion that no significant difference in amount of plasmid in the nuclear fraction was found.

\section{CONCLUSION AND PROSPECTS}

Although DNA nuclear Targeting Sequences can increase nuclear delivery of plasmids, no significant benefits for overall transgene expression are obtained if combined with strong promoters. The added value of DTS may lie in compensating for weak promoters. Weak promoters can be a useful alternative to the strong CMV promoter to minimize immunological responses and promoter shutdown in vivo and for transcriptional targeting.

Besides their relevance for improving efficiency of non-viral gene delivery, DTSs are of value from a mechanistic point of view to gain insight into cytonucleoplasmic transport of macromolecules. In this respect, focusing on well-defined homogeneous DTS is preferred over heterogeneous DTS such as the SV40 enhancer region. Using such homogeneous DTS, research should be directed at studying the nature and kinetics of protein-DNA interaction. First, it would be valuable to identify which proteins interact with a DTS and which of these proteins are able to fulfill a role in facilitating nuclear import of the DTS-containing plasmid. Not all proteins that contain a DNA binding domain and an NLS can act to shuttle DNA into the nucleus, and it is thought that the overall organization and structure of the DNA-TF complex might be important (for example, spacing between the DNA binding domain and the NLS). Subsequently, efforts to optimize interaction between the protein and DNA could be made. Studies performed by Gonçalves et al. (54) show that optimization of the DTS sequence is important and that spacing between repetitive binding sites has a strong effect on transfection efficiency.

Second, it would be interesting to study if and how this interaction takes place with plasmid DNA while complexed with its carrier inside the cell cytosol. Gonçalves et al. (54) performed a cross-linked immunoprecipitation assay with antibodies directed against $\mathrm{NF \kappa B}$ and found that plasmid DNA was present in the immunocomplexes, indicating cytoplasmic interaction of plasmid with NFkB. However, it remains elusive whether this interaction occurred in the presence of carrier, as the carrier is likely to dissociate during the cell work-up which includes triton and SDS treatments. In our hands, treatment with these detergents disassembled plasmid/pEI complexes (not shown). Future studies regarding the kinetics of vector disassembly, the kinetics of transcription factor activation (under normal conditions, in diseased tissues and in response to drugs) and binding of those transcription factors to DTS within the plasmid 'to be delivered' will help to understand and exploit processes by which plasmid DNA can gain access to the cell nucleus.

Open Access This article is distributed under the terms of the Creative Commons Attribution Noncommercial License which permits any noncommercial use, distribution, and reproduction in any medium, provided the original author $(\mathrm{s})$ and source are credited.

\section{REFERENCES}

1. Forrest ML, Pack DW. On the kinetics of polyplex endocytic trafficking: implications for gene delivery vector design. Mol Ther. 2002;6(1):57-66.

2. Funhoff AM, van Nostrum CF, Koning GA, SchuurmansNieuwenbroek NM, Crommelin DJ, Hennink WE. Endosomal escape of polymeric gene delivery complexes is not always enhanced by polymers buffering at low $\mathrm{pH}$. Biomacromolecules. 2004;5(1):32-9.

3. Lechardeur D, Sohn KJ, Haardt M, Joshi PB, Monck M, Graham RW, et al. Metabolic instability of plasmid DNA in the cytosol: a potential barrier to gene transfer. Gene Ther. 1999;6 (4):482-97.

4. Lukacs GL, Haggie P, Seksek O, Lechardeur D, Freedman N, Verkman AS. Size-dependent DNA mobility in cytoplasm and nucleus. J Biol Chem. 2000;275(3):1625-9.

5. Luby-Phelps K. Cytoarchitecture and physical properties of cytoplasm: volume, viscosity, diffusion, intracellular surface area. Int Rev Cytol. 2000;192:189-221.

6. Grosse S, Aron Y, Thevenot G, Monsigny M, Fajac I. Cytoskeletal involvement in the cellular trafficking of plasmid/PEI derivative complexes. J Control Release. 2007;122 (1):111-7.

7. Ondrej V, Lukasova E, Falk M, Kozubek S. The role of actin and microtubule networks in plasmid DNA intracellular trafficking. Acta Biochim Pol. 2007;54(3):657-63.

8. Vaughan EE, Dean DA. Intracellular trafficking of plasmids during transfection is mediated by microtubules. Mol Ther. 2006;13(2):422-8.

9. Vaughan EE, DeGiulio JV, Dean DA. Intracellular trafficking of plasmids for gene therapy: mechanisms of cytoplasmic movement and nuclear import. Curr Gene Ther. 2006;6(6):671-81.

10. van der Aa MA, Koning GA, d'Oliveira C, Oosting RS, Wilschut KJ, Hennink WE, et al. An NLS peptide covalently linked to linear DNA does not enhance transfection efficiency of cationic polymer based gene delivery systems. J Gene Med. 2005;7(2):208-17.

11. Collins E, Birchall JC, Williams JL, Gumbleton M. Nuclear localisation and pDNA condensation in non-viral gene delivery. $\mathrm{J}$ Gene Med. 2007;9(4):265-74.

12. Dean DA, Strong DD, Zimmer WE. Nuclear entry of nonviral vectors. Gene Ther. 2005;12(11):881-90.

13. Escriou V, Carriere M, Scherman D, Wils P. NLS bioconjugates for targeting therapeutic genes to the nucleus. Adv Drug Deliv Rev. 2003;55(2):295-306.

14. Glover DJ, Leyton DL, Moseley GW, Jans DA. The efficiency of nuclear plasmid DNA delivery is a critical determinant of transgene expression at the single cell level. J Gene Med. 2010;12(1):77-85. 
15. Pouton GW, Wagstaff KM, Roth DM, Moseley GW, Jans DA. Targeted delivery to the nucleus. Adv Drug Deliv Rev. 2007;59 (8):698-717.

16. Bieber T, Meissner W, Kostin S, Niemann A, Elsasser HP. Intracellular route and transcriptional competence of polyethylenimine-DNA complexes. J Control Release. 2002;82 (2-3):441-54.

17. Hama S, Akita $\mathrm{H}$, Iida S, Mizuguchi $\mathrm{H}$, Harashima $\mathrm{H}$. Quantitative and mechanism-based investigation of post-nuclear delivery events between adenovirus and lipoplex. Nucleic Acids Res. 2007;35(5):1533-43.

18. Honore I, Grosse S, Frison N, Favatier F, Monsigny M, Fajac I. Transcription of plasmid DNA: influence of plasmid DNA/ polyethylenimine complex formation. J Control Release. 2005; 107(3):537-46.

19. Tachibana R, Ide N, Shinohara Y, Harashima H, Hunt CA, Kiwada H. An assessment of relative transcriptional availability from nonviral vectors. Int J Pharm. 2004;270(1-2):315-21.

20. Capecchi MR. High efficiency transformation by direct microinjection of DNA into cultured mammalian cells. Cell. 1980;22(2 Pt 2):479-88.

21. Adam SA. The nuclear pore complex. Genome Biol. 2001;2(9): REVIEWS0007.

22. Ludtke JJ, Zhang G, Sebestyen MG, Wolff JA. A nuclear localization signal can enhance both the nuclear transport and expression of 1 kb DNA. J Cell Sci. 1999;112(Pt 12):2033-41.

23. Schaffer DV, Fidelman NA, Dan N, Lauffenburger DA. Vector unpacking as a potential barrier for receptor-mediated polyplex gene delivery. Biotechnol Bioeng. 2000;67(5):598-606.

24. Gorlich D, Kutay U. Transport between the cell nucleus and the cytoplasm. Annu Rev Cell Dev Biol. 1999;15:607-60.

25. Branden LJ, Mohamed AJ, Smith CI. A peptide nucleic acidnuclear localization signal fusion that mediates nuclear transport of DNA. Nat Biotechnol. 1999;17(8):784-7.

26. Bremner KH, Seymour LW, Logan A, Read ML. Factors influencing the ability of nuclear localization sequence peptides to enhance nonviral gene delivery. Bioconjug Chem. 2004;15(1):152-61.

27. Carriere M, Escriou V, Savarin A, Scherman D. Coupling of importin beta binding peptide on plasmid DNA: transfection efficiency is increased by modification of lipoplex's physicochemical properties. BMC Biotechnol. 2003;3(1):14.

28. Ciolina C, Byk G, Blanche F, Thuillier V, Scherman D, Wils P. Coupling of nuclear localization signals to plasmid DNA and specific interaction of the conjugates with importin alpha. Bioconjug Chem. 1999;10(1):49-55.

29. Duvshani-Eshet M, Keren H, Oz S, Radzishevsky IS, Mor A, Machluf M. Effect of peptides bearing nuclear localization signals on therapeutic ultrasound mediated gene delivery. J Gene Med. 2008.

30. Sebestyen MG, Ludtke JJ, Bassik MC, Zhang G, Budker V, Lukhtanov EA, et al. DNA vector chemistry: the covalent attachment of signal peptides to plasmid DNA. Nat Biotechnol. 1998;16(1):80-5.

31. Tanimoto M, Kamiya H, Minakawa N, Matsuda A, Harashima $\mathrm{H}$. No enhancement of nuclear entry by direct conjugation of a nuclear localization signal peptide to linearized DNA. Bioconjug Chem. 2003;14(6): 1197-202.

32. Trabulo S, Mano M, Faneca H, Cardoso AL, Duarte S, Henriques A, et al. S4(13)-PV cell penetrating peptide and cationic liposomes act synergistically to mediate intracellular delivery of plasmid DNA. J Gene Med. 2008.

33. Zanta MA, Belguise-Valladier P, Behr JP. Gene delivery: a single nuclear localization signal peptide is sufficient to carry DNA to the cell nucleus. Proc Natl Acad Sci USA. 1999;96(1):91-6.

34. Graessmann M, Menne J, Liebler M, Graeber I, Graessmann A. Helper activity for gene expression, a novel function of the SV40 enhancer. Nucleic Acids Res. 1989;17(16):6603-12.
35. Dean DA. Import of plasmid DNA into the nucleus is sequence specific. Exp Cell Res. 1997;230(2):293-302.

36. Dean DA, Dean BS, Muller S, Smith LC. Sequence requirements for plasmid nuclear import. Exp Cell Res. 1999;253(2):713-22.

37. Vacik J, Dean BS, Zimmer WE, Dean DA. Cell-specific nuclear import of plasmid DNA. Gene Ther. 1999;6(6):1006-14.

38. Li S, MacLaughlin FC, Fewell JG, Gondo M, Wang J, Nicol F, et al. Muscle-specific enhancement of gene expression by incorporation of SV40 enhancer in the expression plasmid. Gene Ther. 2001;8(6):494-7.

39. Young JL, Benoit JN, Dean DA. Effect of a DNA nuclear targeting sequence on gene transfer and expression of plasmids in the intact vasculature. Gene Ther. 2003;10(17):1465-70.

40. Young JL, Zimmer WE, Dean D. Smooth muscle-specific gene delivery in the vasculature based on restriction of DNA nuclear import. Exp Biol Med (Maywood). 2008.

41. Breuzard G, Tertil M, Goncalves C, Cheradame H, Geguan P, Pichon $\mathrm{G}$, et al. Nuclear delivery of $\mathrm{NF}\{$ kappa $\} \mathrm{B}$-assisted DNA/ polymer complexes: plasmid DNA quantitation by confocal laser scanning microscopy and evidence of nuclear polyplexes by FRET imaging. Nucleic Acids Res. 2008;36(12).

42. Mesika A, Grigoreva I, Zohar M, Reich Z. A regulated, NFkappaB-assisted import of plasmid DNA into mammalian cell nuclei. Mol Ther. 2001;3(5 Pt 1):653-7.

43. Mesika A, Kiss V, Brumfeld V, Ghosh G, Reich Z. Enhanced intracellular mobility and nuclear accumulation of DNA plasmids associated with a karyophilic protein. Hum Gene Ther. 2005;16 (2):200-8

44. Dames P, Laner A, Maucksch C, Aneja MK, Rudolph C. Targeting of the glucocorticoid hormone receptor with plasmid DNA comprising glucocorticoid response elements improves nonviral gene transfer efficiency in the lungs of mice. J Gene Med. 2007;9(9):820-9.

45. Zabner J, Fasbender AJ, Moninger T, Poellinger KA, Welsh MJ. Cellular and molecular barriers to gene transfer by a cationic lipid. J Biol Chem. 1995;270(32):18997-9007.

46. Itaka K, Harada A, Yamasaki Y, Nakamura K, Kawaguchi H, Kataoka K. In situ single cell observation by fluorescence resonance energy transfer reveals fast intra-cytoplasmic delivery and easy release of plasmid DNA complexed with linear polyethylenimine. J Gene Med. 2004;6(1):76-84.

47. Cohen RN, van der Aa MA, Macaraeg N, Lee AP, Szoka Jr FC. Quantification of plasmid DNA copies in the nucleus after lipoplex and polyplex transfection. J Control Release. 2009;135 (2):166-74

48. www.stratagene.com. [cited 2009 March 23].

49. Godbey WT, Wu KK, Mikos AG. Tracking the intracellular path of poly(ethylenimine)/DNA complexes for gene delivery. Proc Natl Acad Sci USA. 1999;96(9):5177-81.

50. Pedrali-Noy G, Spadari S, Miller-Faures A, Miller AO, Kruppa J, Koch G. Synchronization of HeLa cell cultures by inhibition of DNA polymerase alpha with aphidicolin. Nucleic Acids Res. 1980;8(2):377-87.

51. Utvik JK, Nja A, Gundersen K. DNA injection into single cells of intact mice. Hum Gene Ther. 1999;10(2):291-300.

52. Ruponen M, Arkko S, Urtti A, Reinisalo M, Ranta VP. Intracellular DNA release and elimination correlate poorly with transgene expression after non-viral transfection. J Control Release. 2009;136(3):226-31.

53. Mortimer I, Tam P, MacLachlan I, Graham RW, Saravolac EG, Joshi PB. Cationic lipid-mediated transfection of cells in culture requires mitotic activity. Gene Ther. 1999;6(3):403-11.

54. Goncalves G, Ardourel MY, Decoville M, Breuzard G, Midoux P, Hartmann B, et al. An optimized extended DNA kappa B site that enhances plasmid DNA nuclear import and gene expression. J Gene Med. 2009;11(5):401-11. 
55. Prasad TK, Rao NM. The role of plasmid constructs containing the SV40 DNA nuclear-targeting sequence in cationic lipid-mediated DNA delivery. Cell Mol Biol Lett. 2005;10(2):203-15.

56. Wilschut KJ, van der Aa MA, Oosting RS, Hennink WE, Koning GA, Crommelin DJ, et al. Fluorescence in situ hybridization to monitor the intracellular location and accessibility of plasmid DNA delivered by cationic polymer-based gene carriers. Eur J Pharm Biopharm. 2009;72(2):391-6.

57. Gasiorowski JZ, Dean DA. Postmitotic nuclear retention of episomal plasmids is altered by DNA labeling and detection methods. Mol Ther. 2005;12(3):460-7.

58. James MB, Giorgio TD. Nuclear-associated plasmid, but not cellassociated plasmid, is correlated with transgene expression in cultured mammalian cells. Mol Ther. 2000;1(4):339-46.

59. Maucksch C, Bohla A, Hoffmann F, Schleef M, Aneja MK, Elfinger M, et al. Transgene expression of transfected supercoiled plasmid DNA concatemers in mammalian cells. J Gene Med. 2009;11(5):444-53.

60. Tachibana R, Harashima H, Ide N, Ukitsu S, Ohta Y, Suzuki N, et al. Quantitative analysis of correlation between number of nuclear plasmids and gene expression activity after transfection with cationic liposomes. Pharm Res. 2002;19(4):377-81.

61. Hama S, Akita H, Ito R, Mizuguchi H, Hayakawa T, Harashima H. Quantitative comparison of intracellular trafficking and nuclear transcription between adenoviral and lipoplex systems. Mol Ther. 2006;13(4):786-94.

62. Foecking MK, Hofstetter H. Powerful and versatile enhancerpromoter unit for mammalian expression vectors. Gene. 1986;45 (1):101-5.

63. Thanaketpaisarn O, Nishikawa M, Okabe T, Yamashita F, Hashida M. Insertion of nuclear factor-kappaB binding sequence into plasmid DNA for increased transgene expression in colon carcinoma cells. J Biotechnol. 2008;133(1):36-41. 